\title{
FORMAÇÃO CONTINUADA DE GESTORES ESCOLARES E SUAS REVERBERAÇÕES NO PROCESSO DE DESENVOLVIMENTO PROFISSIONAL
}

\author{
Francisco Jeovane do NASCIMENTO ${ }^{i}$ \\ Eliziane Rocha CASTRO ${ }^{\text {ii }}$ \\ Luciana Rodrigues LEITE ${ }^{\text {iii }}$ \\ Maria Socorro Lucena LIMA ${ }^{\text {iv }}$
}

\begin{abstract}
RESUMO
O estudo é oriundo da experiência vivenciada por gestores escolares, de instituições públicas de ensino médio da rede estadual do Ceará, em um curso de formação continuada na modalidade EAD, no qual objetivamos averiguar as contribuições e limitações do processo formativo continuado no desenvolvimento profissional dos indivíduos. Em relação à análise de dados, utilizamos a abordagem qualitativa, cujo foco remete à significação atribuída às experiências vivenciadas pelos sujeitos do estudo, seu posicionamento reflexivo/crítico, bem como a averiguação do processo formativo vivenciado. O método adotado nesta investigação foi o estudo de caso e como procedimento de recolha de dados utilizamos o exame documental e a entrevista semiestruturada individual. Constatouse que a formação continuada pautada nas necessidades dos gestores potencializa a instauração de espaços colaborativos de compartilhamento de conhecimentos, experiências, angústias e dificuldades, dentre outros, propiciando reflexões críticas individuais e coletivas estimulando a autonomia e mobilização coletiva de luta por melhorias nas condições de trabalho, objetivando valorização dos profissionais da educação. Infere-se a importância da disponibilidade de tempo e espaço para reflexões mais aprofundadas, de forma que possam ser vislumbradas como aportes contributivos no trabalho dos gestores e em seu processo de desenvolvimento profissional.
\end{abstract}

PALAVRAS-CHAVE: Formação continuada; Possibilidades/desafios; Desenvolvimento profissional.

\section{CONTINUING EDUCATION OF SCHOOL MANAGERS AND THEIR REVERBERATIONS IN THE PROCESS OF PROFESSIONAL DEVELOPMENT}

\footnotetext{
${ }^{\text {i }}$ Doutorando em Educação pela Universidade Estadual do Ceará (UECE); Professor da rede estadual de ensino do Ceará (SEDUC/CE). E-mail: jeonasc@ hotmail.com.

ii Doutoranda em Educação pela Universidade Estadual do Ceará (UECE); Professora da rede municipal de ensino de Raposa/MA. E-mail: elizianecastro@ hotmail.com.

iii Doutoranda em Educação pela Universidade Estadual do Ceará (UECE); Professora do curso de Química da Universidade Estadual Vale do Acaraú (UVA/CE). E-mail: lurodleite@gmail.com.

iv Doutora e Pós-Doutora em Educação pela Universidade de São Paulo (USP); Professora e Pesquisadora do Programa de Pós-Graduação em Educação da Universidade Estadual do Ceará (UECE); Professora Visitante da Universidade da Integração Internacional da Lusofonia Afro-Brasileira (UNILAB). E-mail: azeriche@hotmail.com.
} 


\section{ABSTRACT}

The study comes from experiences learned by school administrators from public institutions of the state network of Ceara, at a training course in the modality EAD in which we aim to analyze contribuitions and difficulties in their professional development. As to data analyses we use the qualitative approaches, where the focus shows the work attributed by them and also showing commitment and work. We use as research three methods: data collection, documentary examination, individual interview. The continuing education based on the need of managers empower collaborative spaces and help to share knowledge, experience, difficulties among outhers. This also helps to create collectives and individual opinions and thus helping both by improvement in the scope of working and the valuation of the education professional. So we concluded the importance of the availability of time and space for better details and that fact can be important in the process of vocational training for both.

KEYWORDS: Continuing education; Possibilities/challenges; Professional development.

\section{FORMACIÓN CONTINUADA DE GESTORES ESCOLARES Y SUS REVERBERCIONES EN EL PROCESO DE DESARROLLO PROFESIONAL}

\section{RESUMEN}

El estudio es oriundo de la experiencia vivenciada por gestores escolares, de instituciones públicas de enseñanza media de la red estadual de Ceará, en un curso de formación continuada en la modalidad $E A D$, en el cual objetivamos averiguar las contribuciones y limitaciones del proceso formativo continuado en el desarrollo profesional de los individuos. En cuanto al análisis de datos, utilizamos el abordaje cualitativo, en que el foco remite la significación atribuida a las experiencias vivenciadas por los sujetos del estudio, su posicionamiento reflexivo / crítico, así como la averiguación del proceso formativo vivenciado. Como metodología de la investigación optamos por el estudio de caso y como procedimiento de recogida de datos, utilizamos el examen documental y la entrevista semiestructurada individual. La formación continuada pautada en las necesidades de los gestores potencializa la instauración de espacios colaborativos de intercambio de conocimientos, experiencias, angustias y dificultades, entre otros, propiciando reflexiones críticas individuales y colectivas estimulando la autonomía y movilización colectiva de lucha por mejoras en las condiciones de trabajo, objetivando valorización de los profesionales de la educación. Se infiere la importancia de la disponibilidad de tiempo y espacio para reflexiones más profundas, de forma que puedan ser vislumbradas como aportes contributivos en el trabajo de los gestores y en su proceso de desarrollo profesional.

PALABRAS CLAVE: Formación continuada; Oportunidades / desafíos; Desarrollo professional.

\section{INTRODUÇÃO}

O presente estudo é oriundo da experiência vivenciada por um grupo de dez sujeitos, dentre diretores e coordenadores pedagógicos de cinco instituições escolares, que atendem 
estudantes do Ensino Médio e integram a rede pública estadual do Ceará, em um curso de formação continuada na modalidade Educação à Distância (EAD), no qual objetivou-se averiguar as contribuições e limitações do processo formativo continuado no desenvolvimento profissional dos indivíduos.

A experiência formativa vivenciada pelos sujeitos desta investigação remete à participação no Curso de Atualização em Gestão Escolar, desenvolvido pelo Centro de Educação à Distância do Ceará (CED), órgão vinculado à Secretaria de Educação Básica do Estado do Ceará (SEDUC/CE). Esse curso foi delineado totalmente na modalidade EAD, mediante a utilização do Ambiente Virtual de Aprendizagem do Centro de Educação a Distância (AVACED), desenvolvido pelos profissionais do CED.

As atividades do curso supracitado foram desenvolvidas entre dezembro de 2017 e janeiro de 2018, com uma carga horária de 100 horas, tendo como público-alvo todos os gestores que integravam as instituições escolares da rede estadual do Ceará, dentre diretores e coordenadores pedagógicos, e se constituiu como exigência mínima para participação no processo de eleição para gestão das escolas da rede pública estadual cearense.

Nesse aspecto, os diretores das escolas regulares da rede pública cearense são eleitos por votação direta, na qual participam alunos, professores e responsáveis por estudantes menores de 16 anos, em conformidade com o que explicita a Lei ${ }^{\circ} 13.513$, de 19 de julho de 2004 (CEARÁ, 2004), publicada no Diário Oficial do estado do Ceará, que em seu artigo segundo expõe o seguinte:

O processo de escolha e indicação para o provimento do cargo em comissão de Diretor junto às Escolas Públicas Estaduais do Ensino Básico será realizado em duas etapas:

I - Primeira Etapa: terá caráter eliminatório, constando de avaliação escrita e exame de títulos;

II - Segunda Etapa: realização de eleição direta e secreta, mediante sufrágio universal, junto à Comunidade Escolar, podendo dela participar apenas os candidatos que obtiverem, na etapa anterior, média igual ou superior a 6,0 (seis), numa escala de zero a 10,0 (dez).

Destarte, para o pleito relativo ao início de 2018, período em que foi realizada a eleição para escolha dos diretores escolares, a primeira etapa foi substituída pela realização do curso de Atualização em Gestão Escolar, em conformidade com a proposta de Lei $\mathrm{n}^{\circ}$ 16.379, de 16 de outubro de 2017 (CEARÁ, 2017), que alterou a legislação vigente. 
De acordo com consulta realizada no site da Secretaria de Educação Básica do Estado do Ceará (SEDUC/CE), o curso teve a participação inicial de 3.490 cursistas, dentre diretores escolares e coordenadores pedagógicos. Todavia, concluíram o processo formativo, 3.351 cursistas, pouco mais de $96 \%$ dos que iniciaram o percurso formativo. Por conseguinte, o foco do nosso estudo remete à análise das contribuições e limitações do processo formativo continuado no desenvolvimento profissional de um grupo de indivíduos, participantes desse curso, em alusão aos conhecimentos trabalhados na proposta formativa e suas reverberações na ação dos profissionais que vivenciaram tal experiência.

\section{A FORMAÇÃo CONTINUAdA COMO ELEMENTO CONTRIBUINTE NO DESENVOLVIMENTO PROFISSIONAL}

Conforme Nascimento (2016), o desenvolvimento profissional é um processo que almeja contribuir na melhoria da atividade docente, perpassando a história de vida do professor, sua formação inicial, as condições sob as quais o mesmo exerce a sua atividade profissional, além das indagações pertinentes às questões pessoais e profissionais docentes. Esses fatores influenciam na ampliação dos conhecimentos relativos à profissão e questões práticas, além da ampliação de estratégias que tendem a subsidiar a melhoria do trabalho docente em sala de aula.

É desse modo que o desenvolvimento profissional, como um processo, viabiliza melhorias concernentes à ação educativa. Permeia questões pessoais e relacionadas ao trabalho exercido, remetendo à individualidade inerente à singularidade de cada indivíduo, mas perpassando o viés coletivo e colaborativo com foco na melhoria de todo o grupo, fator essencial para o trabalho de uma gestão escolar, que conduz o delineamento organizacional e funcional de uma escola, em um contexto específico.

Ademais, Marcelo (2009) explicita que o processo de desenvolvimento profissional é algo contínuo, acontecendo ao longo da carreira no contexto educacional, de forma individual e coletiva, tendo a escola (local de atuação docente) como um espaço de efetivação desse processo, que vai se reconfigurando mediante as experiências, formais e informais, vivenciadas pelo educador em sua trajetória de vida e profissão. Daí a importância da 
formação continuada e que o profissional da educação perceba a necessidade da continuidade dos estudos, em adequação às mudanças sociais que repercutem e impactam no contexto social, requerendo atualização e incremento do repertório de práticas e saberes relacionados à docência.

Entende-se o processo de formação continuada como um dos vieses que possibilita aos educadores o princípio reflexivo, na perspectiva de redirecionamento das ações didático/pedagógicas, buscando a constante reconstrução do repertório de conhecimentos e estratégias que propiciem um exercício mais qualificado da ação profissional (SILVA, 2013). Nesse aspecto, a aprendizagem não remete apenas ao contexto da sala de aula, mas a todo o ambiente que permeia a escola e ao próprio contexto social, fruto das interações permanentes entre os seres humanos.

O processo de formação continuada tende a favorecer o aperfeiçoamento de habilidades e competências docentes que possam incrementar as estratégias desenvolvidas no espaço escolar, almejando a aprendizagem significativa (OLIVEIRA-FORMOSINHO, 2009). Complementando, Mizukami (2013, p. 28) expõe que

Aprender ao longo da vida implica mudanças de teorias pessoais, de valores, de práticas [...] e a conceberem a profissão não reduzida ao domínio de conceitos de uma área específica. Implica, igualmente, o desenvolvimento de habilidades, atitudes, comprometimento, investigação da própria atuação, disposição de trabalhar com os pares, avaliação de seus próprios desempenhos e procura constante de formas de melhoria de sua prática pedagógica em relação a populações específicas com as quais interagem.

Silva (2013) advoga que o conhecimento encontra-se em constante processo de reconstrução, resultante das transformações sociais, econômicas e tecnológicas que permeiam o cotidiano dos indivíduos, de forma que é uma tarefa inerente ao profissional da docência o constante processo formativo, na perspectiva de possibilitar a sistematização do conhecimento com um sentido, um valor e uma finalidade na vida dos indivíduos com os quais interage.

Nesse aspecto, as tecnologias da informação e comunicação se evidenciam como mecanismos que possibilitam a continuidade formativa ao longo da vida, se adequando às peculiaridades de cada indivíduo, considerando questões como indisponibilidade de tempo e/ou impossibilidade de frequência em um local físico que ofereça uma formação específica ou se enquadre aos anseios e necessidades de cada profissional, dentre outras. Ressalta-se a 
necessidade do desenvolvimento de uma rotina de estudos pessoais, em que a formação possa contribuir na vida e trabalho docente e não seja vislumbrada apenas como forma de obtenção de uma certificação que não propicia novas formas de abordagem da realidade.

A formação continuada deve proporcionar ao profissional em exercício, a (re)construção de saberes inerentes ao seu trabalho cotidiano, alicerçados em conhecimentos didático-pedagógicos que relacionem a teoria e a prática e repercutam na sistematização dos saberes curriculares, pois Imbernón (2010) expõe que a formação será legítima quando contribuir para o desenvolvimento profissional do professor no âmbito de trabalho e de melhoria das aprendizagens profissionais.

A Lei $n^{\circ}$ 9.394/96, intitulada Lei Diretrizes e Bases da Educação Nacional, assegura o direito de oferta de formação continuada aos profissionais em serviço (BRASIL, 1996), no qual a Resolução $n^{\circ} 2$, de $1^{\circ}$ de julho de 2015 que explicita as diretrizes curriculares nacionais para a formação inicial em nível superior e para a formação continuada, expõe no artigo 16 que o processo formativo continuado tem como finalidade principal "[...] a reflexão sobre a prática educacional e a busca de aperfeiçoamento técnico, pedagógico, ético e político do profissional docente" (BRASIL, 2015, p. 13). Englobam-se vários aspectos que são importantes na ação profissional, superando uma visão reducionista de enfoque na dimensão técnica, que é essencial, mas não exclusiva, requerendo o atrelamento com outros elementos que podem potencializar um trabalho mais qualificado da docência.

A resolução $\mathrm{n}^{\circ} 2$, de $1^{\circ}$ de julho de 2015 (BRASIL, 2015, p. 14) expressa, também, em seu artigo 16, parágrafo único, que

A formação continuada decorre de uma concepção de desenvolvimento profissional dos profissionais do magistério que leva em conta:

I - os sistemas e as redes de ensino, o projeto pedagógico das instituições de educação básica, bem como os problemas e os desafios da escola e do contexto onde ela está inserida;

II - a necessidade de acompanhar a inovação e o desenvolvimento associados ao conhecimento, à ciência e à tecnologia;

III - o respeito ao protagonismo do professor e a um espaço-tempo que lhe permita refletir criticamente e aperfeiçoar sua prática;

IV - o diálogo e a parceria com atores e instituições competentes, capazes de contribuir para alavancar novos patamares de qualidade ao complexo trabalho de gestão da sala de aula e da instituição educativa. 
Desta forma, evoca-se o processo de formação continuada como um dos elementos contribuintes no desenvolvimento profissional docente, permeando a compreensão interpretativa acerca da conjuntura que norteia a escola, englobando aspectos culturais e sociais, que interferem no fazer pedagógico, bem como as necessidades dos professores e educandos que compõem a instituição escolar, com foco no diálogo efetivo com vistas a instauração de um ambiente escolar democrático, que busque o consenso por objetivos comuns e almeje a melhoria contínua da escola e de todos os profissionais que a compõem.

Assim, este estudo ganha relevância pela necessidade de uma análise sobre as contribuições e desafios da formação continuada no processo de desenvolvimento profissional de gestores escolares, visto que os conhecimentos da profissão evoluem e progridem, necessitando de constante formação continuada. Ademais, afirma-se com Lima (2012, p. 55) que "acreditamos que a formação contínua não se efetiva distanciada de um projeto de desenvolvimento profissional que a sustente, estando implícito nisso os sonhos, a vida e o trabalho do professor".

Advoga-se o desenvolvimento de ações formativas embasadas nas premências docentes, estimulando a aprendizagem colaborativa no contexto escolar, no qual a gestão e todos os professores sintam-se responsáveis pela busca por melhorias que beneficiem toda a comunidade escolar, em um projeto comum, não dissociado, com interesses divergentes e individualizados. Nesses termos, infere-se que o processo de formação continuada reverbere, não somente, em aspectos que permeiam o trabalho dos gestores e professores, mas também em questões individuais, tornando-os melhores pessoas, promovendo a humanização e engajando-os na luta social coletiva. Entretanto, nem sempre é o que ocorre, conforme denunciam Mattos e Mattos (2018, p. 39):

[...] Em alguns cursos de formação de professores, ainda hoje, vemos práticas centradas em uma lógica tradicional transmissiva que não tem relação com o cotidiano escolar nem tão pouco com as necessidades existentes em sala de aula. Outros possuem um caráter individualista, marcados por um modelo tecnicista, com ações isoladas e pontuais. E há outros, ainda, que visam à indústria de formação, em que ela é tida como mercadoria, e cabe aos professores colecionar certificados.

O processo de formação continuada deve focalizar o profissional da educação como participante e protagonista do processo, no qual gestor/professor não seja apenas um receptor 
de informações, mas um sujeito atuante que dialoga, reflete, interpreta, infere e produz conhecimentos no âmbito da sua profissão, em adequação às necessidades contemporâneas, que se transformam continuamente, exigindo uma formação pautada na realidade das escolas com seus dilemas e especificidades próprias e não na idealização de modelos perfeitos para instituições escolares que não existem.

\section{PROCEDIMENTOS METODOLÓGICOS}

A pesquisa é composta por cinco participantes do sexo masculino (dois diretores escolares e três coordenadores pedagógicos) e cinco do sexo feminino (três diretoras e duas coordenadoras). Explicita-se que a escolha de tal amostra tornou-se possível devido à disponibilidade dos sujeitos em contribuírem, de forma voluntária, no estudo. Foi feito o contato com profissionais que vivenciaram a experiência formativa, pelo qual se recebeu um retorno de dez indivíduos, que compõem a amostra do referido estudo.

Os sujeitos desenvolvem sua atividade profissional em cinco instituições diferentes, encravadas na região norte do estado do Ceará. Não serão citados os nomes das escolas onde os indivíduos trabalham por razões éticas. Existem cidades com apenas uma escola da rede estadual, de modo que a referência a tal instituição poderia conduzir à identificação do participante, ferindo os princípios éticos do estudo.

Em relação à análise de dados, utilizou-se a abordagem qualitativa, na perspectiva de Ponte (2006), em que o foco remete à significação atribuída às experiências vivenciadas pelos sujeitos do estudo, permeando sua trajetória de vida e trabalho, seu posicionamento reflexivo/crítico, bem como a averiguação do processo formativo vivenciado. Nesse aspecto, o autor supracitado expõe a relevância do pesquisador, em que este se constitui "no principal instrumento [...] não havendo nada que substitua a sua perspicácia observadora, bem como a riqueza e pertinência das suas perspectivas de análise" (PONTE, 2006, p. 20). Compreende-se a pesquisa como instrumento profícuo de sistematização de conhecimentos, em que o pesquisador deve atentar para o rigor científico e as questões éticas, sob o risco de chegar apenas a constatações óbvias e/ou reforço do senso comum. 
Assim, justifica-se a escolha pela abordagem qualitativa, visto que foram os sujeitos da pesquisa - coordenadores e diretores que vivenciaram a experiência formativa no curso de atualização em gestão escolar - que propiciaram respostas às indagações propostas na realização da investigação científica.

Em relação à metodologia da pesquisa, optou-se pelo estudo de caso, na perspectiva de Ponte (2006, p. 2), que destaca

É uma investigação que se assume como particularística, isto é, que se debruça deliberadamente sobre uma situação específica que se propõe ser única em muitos aspectos, procurando descobrir o que há nela de mais essencial e característico e, desse modo, contribuir para a compreensão global do fenômeno de interesse (PONTE, 2006, p. 2).

O estudo de caso potencializa a análise mais fidedigna de um determinado fenômeno, mediante situações reais, ocorrendo de forma natural por intermédio das experiências e vivências cotidianas, ancorada por uma orientação teórica embasadora que lhe proporcione sustentação e significação, servindo, também, como perspectiva auxiliar na elaboração das indagações inerentes ao estudo, bem como na escolha de instrumentais pertinentes à obtenção de dados.

Nesse sentido, salienta-se que o estudo de caso tem como uma das suas características intrínsecas o detalhamento analítico de um determinado caso. Diante disso, afirma-se que por meio do estudo de caso objetiva-se analisar um fenômeno que concerne ao desenvolvimento profissional dos gestores escolares, com enfoque analítico na formação continuada, por intermédio da participação dos sujeitos no curso de Atualização em Gestão Escolar, promovido pela SEDUC/CE e desenvolvido pelo CED/CE.

Como procedimento de recolha de dados, utilizou-se o exame documental e a entrevista semiestruturada individual, realizada com cada um dos sujeitos do estudo.

A pesquisa foi dividida em duas etapas. Na primeira, realizou-se uma análise crítica/interpretativa das temáticas trabalhadas no decorrer do curso de atualização em gestão escolar, averiguando sua relevância e limitação no processo formativo continuado destinado aos gestores. A segunda etapa contemplou entrevista semiestruturada com os sujeitos do estudo, objetivando escutá-los acerca das contribuições e desafios do processo formativo continuado vivenciado, verificando se o mesmo se constituiu (ou não) como elemento reverberante no desenvolvimento profissional dos sujeitos. 


\section{ANÁLISE DOS CONTEÚdOS PROGRAMÁTICOS ABORDADOS NO PERCURSO DA FORMAÇÃO CONTINUADA}

No que remete a análise crítico/interpretativa dos conteúdos abordados no percurso da formação continuada, inerente ao delineamento das ações do curso de atualização em gestão escolar, constatou-se que o mesmo foi dividido em módulos, em que o primeiro tópico abordado, com carga horária de 10 horas, remeteu ao debate sobre a relevância das Tecnologias da Informação e Comunicação (TIC) no contexto contemporâneo, assim como a importância relacionada à formação continuada dos gestores, buscando melhorias que reverberem em aspectos pessoais e profissionais, com foco em ações que objetivam elementos comuns, visto que no processo de desenvolvimento da profissionalidade docente "[...] é impossível separar as dimensões pessoais e profissionais"(NÓVOA, 2009, p. 38).

Nesse aspecto, os profissionais da educação devem vislumbrar a continuidade formativa ao longo da vida como um elemento que pode possibilitar auxílio e aporte em sua ação cotidiana, permeando seus anseios pessoais, valorização e realização no âmbito do trabalho. Permeia, também, a presença das TIC no cotidiano pessoal dos indivíduos, pois estas podem ser evidenciadas como instrumentos de estudo pessoais e coletivos, em uma perspectiva de incentivo à autonomia discente, em que a escola seja vislumbrada como local privilegiado de construção e/ou sistematização de conhecimentos, mas não exclusivo, emergindo outras possibilidades conducentes a efetivação da aprendizagem.

No segundo módulo, com um tempo estipulado em 10 horas, foram enfatizados estudos concernentes à legislação educacional vigente, contemplando debates sobre a Lei $\mathrm{n}^{\circ}$ 9.394/96 (LDB), com referências à Base Nacional Comum Curricular (BNCC); Estatuto da Criança e do Adolescente (ECA), regido pela Lei no 8.069/90 (BRASIL, 1990), bem como a Lei n ${ }^{\circ}$ 16.287/2017 (CEARÁ, 2017), que instituiu a política de Ensino Médio integral na rede de ensino do estado do Ceará. Este módulo foi composto por debates acerca das ações propostas por organismos políticos/educacionais, que impactam e reverberam na vida e trabalho dos professores, gestores e escolas, no qual é mister o conhecimento legislatório, na perspectiva de formação de profissionais críticos/reflexivos que se engajem em mobilizações 
por melhorias coletivas, de forma que a legislação possa estar em sintonia com a realidade das escolas e dos profissionais que nela exercem o seu trabalho (NASCIMENTO, 2016).

Com uma carga horária estipulada em 30 horas, o módulo três abordou assuntos referentes a gestão democrática e participativa, abrangendo também a construção coletiva do Projeto Político Pedagógico (PPP) em consonância com a realidade das instituições escolares; conselho escolar; conselho de classe; unidade executora dos recursos financeiros e a relevância do grêmio estudantil nas escolas. Como uma instituição que abrange indivíduos com diferentes opiniões e posicionamentos, a escola pode se constituir como um ambiente democrático e de busca por objetivos comuns, bem como um local de imposição de autoridade hierárquica, em que a gestão planeje e caiba aos professores a mera execução.

Nesse aspecto, Lima (2012) advoga a instauração de um contexto participativo, em que as opiniões de todos os indivíduos possam ser ouvidas, objetivando tracejar um planejamento exequível e em consonância com a realidade cultural e social que perpassa o entorno da comunidade escolar, com foco em melhorias que beneficiem todos, com base no diálogo efetivo e vistas a um processo de ensino conducente a aprendizagem e que reverbere positivamente na qualidade educacional.

Emerge a importância da gestão participativa, mediante a instauração de ambientes crítico/dialógicos em que os gestores saibam escutar a opinião da comunidade escolar sem interpretar tal discurso como algo pessoal e de confronto ao status quo, mas que sirva como parâmetro reflexivo e que oportunize a tomada coletiva de ações que repercutem na vida dos professores, dos alunos, bem como na instituição escolar. Sobre esse contexto, Day (2001, p. 190) afirma que "[...] outras vozes, apesar de serem potencialmente dissonantes, são importantes na construção de um diálogo contínuo nas comunidades de aprendizagem".

No módulo de número quatro, que perfez uma carga de 40 horas, os estudos foram concentrados na gestão pedagógica da escola e de resultados educacionais, abrangendo também questões sobre avaliação e a escola como espaço de formação em serviço. Os resultados de aprendizagem devem ser vislumbrados como um construto, regido por um processo participativo e de engajamento de todos os envolvidos no percurso: professores, alunos, família e gestão e não como uma mera ação pautada no resultado por si mesmo, sem objetividade e conhecimento das potencialidades e limitações dos estudantes e docentes. Assim, importa o estímulo à aprendizagem contínua dos educadores, na perspectiva de 
melhorarem como pessoas e como profissionais, repercutindo no espaço escolar, em uma visão individual e coletiva (DAY, 2001).

Infere-se, também, que a avaliação deve ser vislumbrada como um mecanismo de planejamento e redirecionamento de ações e não como um mero instrumento classificatório dos estudantes e que as gestões, instituições escolares e organismos político-educacionais devem estimular e potencializar condições para que os professores deem continuidade à sua formação ao longo da vida, de forma a reverberar em aspectos pessoais e no desenvolvimento de estratégias e ações que repercutam em aulas mais qualificadas, metodologias diversificadas, instauração de ambientes colaborativos, dentre outros, com vistas ao desenvolvimento docente, acreditando que tal fator poderá contribuir na efetivação da aprendizagem dos estudantes e na perspectiva da escola como um ambiente de inclusão e transformação social.

No módulo final, os estudos remeteram à abordagem do Sistema de Gestão Escolar (SIGE), criado e gerenciado pela SEDUC/CE como uma ferramenta de gestão administrativa e de auxílio ao trabalho de gestores e professores. O sistema abrange vários mecanismos interligados que possibilitam aos gestores o acompanhamento e monitoramento de questões como a infrequência escolar e o rendimento dos estudantes em cada uma das disciplinas do currículo, dentre outros aspectos.

Aos professores é disponibilizado o diário online para registrar a frequência dos educandos e o resumo das aulas, além do banco de questões. Neste espaço, os professores das diferentes disciplinas podem consultar e obter atividades sobre os mais variados assuntos que permeiam o currículo escolar, no qual se ressalta que tais questões são elaboradas pelos próprios docentes e qualquer professor da rede estadual pode contribuir com questionamentos, que são avaliados e acrescentados ao banco. Aos alunos é disponibilizado o espaço do aluno online, onde podem verificar questões como rendimento nas disciplinas, infrequência e acesso a materiais de estudo que podem ser disponibilizados pelos docentes das diferentes disciplinas que compõem o currículo escolar.

A busca pela qualidade educacional permeia as condições de trabalho disponibilizadas aos professores e a infraestrutura escolar, sendo importante o auxílio e novos aportes ao trabalho docente e das gestões escolares, contribuindo no incremento de estratégias que 
possam ser utilizadas pelos profissionais conforme seus anseios e necessidades individuais e coletivas em um determinado contexto específico (NASCIMENTO, 2016).

\section{CONTRIBUIÇÕES E DESAFIOS DO PROCESSO FORMATIVO VIVENCIADO PELOS SUJEITOS: REVERBERAÇÕES NO DESENVOLVIMENTO PROFISSIONAL}

$\mathrm{Na}$ etapa posterior da pesquisa, os sujeitos foram ouvidos, por intermédio de uma entrevista semiestruturada individual, sobre as contribuições e desafios da experiência formativa vivenciada no processo de formação continuada, por meio de sua participação no curso de Atualização em Gestão Escolar.

Ressalta-se que os sujeitos do estudo foram professores da rede estadual de ensino, que ocupam o cargo de gestor escolar (diretores e coordenadores) e participaram da formação continuada. Os cinco indivíduos do sexo masculino são dois diretores escolares (um com formação em Educação Física e outro em Matemática) e três coordenadores pedagógicos (formados em Biologia, Geografia e Letras). As mulheres participantes do estudo são três diretoras (uma com formação em História, outra em Matemática e a terceira é licenciada em Química) e duas coordenadoras pedagógicas (formadas em Ciências Sociais e Filosofia).

Em relação às contribuições do processo formativo vivenciado, todos os sujeitos citaram a relevância da aprendizagem colaborativa propiciada pelo processo, enfatizando a troca mútua de conhecimentos e experiências realizada nos fóruns de discussão, que se constituíram como espaços efetivos de diálogo. Nesse espaço, cada indivíduo tinha a oportunidade de relatar histórias de sucesso e de fracasso. Dessa forma, propiciou-se um olhar para o outro, verificando divergências e convergências, na objetividade de redirecionamento de ações que possibilitem uma escola mais democrática e uma gestão mais participativa. Esse contexto é relatado na fala da coordenadora, formada em Ciências Sociais

A cada exposição dos colegas do curso eu percebia que a angústia não era apenas minha e que ali eu poderia expor as dificuldades que eu enfrentava, que serviria como espaço para debater, buscando soluções que eu pudesse adaptar a minha realidade, na perspectiva de discutir com meu grupo de professores ações que possam nos auxiliar em nossa prática, em que nossa escola possa crescer mediante um planejamento comum e voltado para a aprendizagem dos estudantes que acolhemos. 
Nesse aspecto, Nóvoa (2009) expõe a relevância da instauração de um ambiente colaborativo e de compartilhamento de experiências exitosas, bem como de dilemas que permeiam a profissão, investindo em redes de trabalho coletivas embasadas no diálogo e na partilha, potencializando a reflexão crítica, na objetividade de redirecionamento de ações e práticas que tornem a escola um ambiente democrático e participativo.

Outro fator explicitado remeteu à possibilidade de atualização e análise crítica acerca da legislação educacional, bem como à abordagem sobre instrumentos de gestão, elemento citado por sete sujeitos, relatando a oportunidade de estudos sobre leis que versam sobre a educação, em uma via de luta pela equidade entre a legislação e a realidade das escolas, objetivando a mobilização por condições efetivas de trabalho que possam reverberar no labor das escolas e dos professores. Com efeito, o diretor, licenciado em Educação Física afirmou que

O curso propiciou uma oportunidade de conhecimentos e debates sobre a legislação educacional e as necessidades práticas das escolas, no qual a gente possa se atualizar sobre fatores que repercutem e influenciam na nossa ação, em que os gestores de todo estado puderam trocar conhecimentos e propostas que podem conduzir a melhorias que beneficiem toda a comunidade escolar. Pude expor as histórias de sucesso e fracasso que vivenciei e vivencio em meu trabalho cotidiano, no qual considero que os conteúdos abordados propiciaram reflexões com foco em mudanças positivas.

O processo formativo continuado deve oportunizar aos sujeitos conhecimentos que repercutam na melhoria da sua ação profissional, permeando a questão dos debates legislatórios, de forma que os profissionais da educação possam conhecer para interpretar e cobrar dos legisladores políticas públicas exequíveis com a realidade das escolas, de forma que possam reverberar no trabalho das gestões escolares, professores e escolas. Complementando esta compreensão, Silva e Cabral (2016, p.213) afirmam que

A política de formação continuada de professores em serviço deve atender às suas necessidades, por isso as metas e as ações devem ser planejadas sob o ponto de vista da escola, levando em conta as experiências e saberes dos professores, vistos como principais agentes de transformação.

Desse modo, os gestores escolares/professores são vislumbrados como sujeitos que devem ser compreendidos como agentes importantes na busca por efetivação de mudanças 
nos espaços escolares, importando considerar sua opinião e os conhecimentos que possuem, servindo de mote para o planejamento das ações que possam ter impactos na formação e trabalho docente, adequando-se as necessidades teórico/práticas dos indivíduos.

Outro fator citado por todos os sujeitos como contribuinte no trabalho dos gestores escolares remeteu à gestão democrática e participativa, com foco na busca por resultados satisfatórios de aprendizagem, permeando um ambiente dialógico, em que a tomada de decisões seja pautada nas necessidades coletivas e reais do contexto que circunda a instituição escolar e não apenas idealizada ou pautada em modelos oriundos de outros ambientes, sem adequações prévias. Nesse viés, o coordenador, licenciado em Geografia expôs que

A gestão tem que ser aberta a opinião dos professores, alunos e comunidade escolar, no qual o curso enfocou esse aspecto, discutindo a importância democrática, em que a gestão simplesmente não imponha o que tenha que ser feito, mas que discuta coletivamente caminhos viáveis e que proporcionem a superação de problemas que afetam a escola. Nesse sentido, os resultados satisfatórios são advindos da união de toda a comunidade escolar e a gestão tem que ouvir todos, ainda que sejam opiniões contrárias, mas o que está em jogo é o fator coletivo e não a mera individualidade.

Não é possível a superação de um panorama educacional sem a participação e o engajamento da escola, dos professores, comunidade escolar, sociedade e organismos educacionais, no qual possam estabelecer objetivos comuns que propiciem condições plenas para que as gestões escolares/professores possam desempenhar com maestria a sua atividade profissional, com possibilidades formativas ao longo da carreira e de busca por incremento do seu repertório de práticas e conhecimentos, em um contínuo processo de desenvolvimento no âmbito da docência (MATTOS; MATTOS, 2018).

Nesse sentido, foram citados, ainda, como elementos contribuintes as questões relativas ao uso dos sistemas tecnológicos no monitoramento da infrequência e rendimentos dos estudantes, possibilitando acompanhamento e busca por planejamento de ações que contribuam na resolução de tais entraves, de forma que a gestão possa auxiliar o trabalho dos professores. Nesse aspecto, destaca-se o apoio da gestão escolar, de forma a auxiliar e fornecer subsídios ao trabalho do professor. Ao ensejo dessa consideração, Libâneo, Oliveira e Toschi (2009, p. 309) afirmam que “[...] o grande objetivo das escolas é a aprendizagem dos alunos e a organização escolar necessária é a que leva a melhorar a qualidade dessa 
aprendizagem. Portanto o trabalho na sala de aula é a razão de ser da organização e da gestão".

Também foi citado como aspecto positivo, pelos sujeitos da pesquisa, a questão relativa à oferta do curso da modalidade $\mathrm{EAD}$, que possibilitou o estabelecimento de uma rotina de estudos pessoais em conformidade com as necessidades pessoais de cada indivíduo, que necessitam conciliar a rotina de trabalho com a vida pessoal, o que inviabiliza, por vezes, a frequência em um curso presencial.

Como desafio inerente à proposta formativa continuada, todos os sujeitos foram enfáticos em relação ao fator temporal, que é algo necessário no processo formativo, com vistas à efetivação da aprendizagem dos conteúdos explorados, requerendo tempo para reflexões e possíveis adaptações na prática cotidiana. Nessa direção, a diretora, formada em História afirmou que

O tempo de realização do curso, considero, que foi insuficiente, já que em dois meses foram debatidos uma gama variada de assuntos importantes que poderiam ter sido discutidos em um espaço maior de tempo, gerando maiores discussões e proporcionando mais conhecimentos. De todo modo, a iniciativa é louvável, já que o gestor, assim como o professor, necessita de uma formação continuada ao longo da sua carreira.

O processo de formação continuada deve ser abordado como uma ação reflexiva sobre as práticas desenvolvidas nas instituições escolares, com gestores ou professores, que necessitam de redirecionamentos em virtude das mudanças no contexto social contemporâneo, devendo considerar o profissional em serviço não como um objeto manipulativo, mas como sujeito, uma vez que o mesmo traz consigo experiências e conhecimentos teóricos que embasam sua prática, ainda que de forma implícita, pois isso requer tempo para possíveis mudanças (SILVA; CABRAL, 2016).

Outro fator limitador, que os sujeitos citaram, remeteu à questão da ação pontual da iniciativa, sendo sugerida a continuidade formativa, com a oferta de cursos voltados para os gestores escolares, com temáticas que permeiam a sua ação cotidiana. Nesse sentido, o coordenador, licenciado em Biologia explicitou que

A iniciativa foi muito importante, no qual deveria ter continuidade, com a oferta periódica de cursos voltados para os gestores, debatendo assuntos que 
possam contribuir em melhorias nas escolas, promovendo debates e troca de experiências que possam ser adaptadas a outras realidades, objetivando novos olhares sobre o trabalho docente em nossas escolas, em uma visão formativa ao longo da carreira.

Pimenta e Lima (2012) apontam a necessidade da formação ser vislumbrada como algo importante durante a trajetória docente, mediante as novas exigências que o contexto contemporâneo evidencia, ressignificando práticas e saberes que concorram para uma melhor atuação profissional, permeada por políticas públicas que contribuam no trabalho das gestões escolares e dos professores, objetivando uma escola mais democrática e com um processo de ensino conducente à efetivação da aprendizagem, em que a formação seja denotada como um elemento contribuinte no processo de desenvolvimento dos profissionais da educação.

\section{CONSIDERAÇÕES FINAIS}

No cenário contemporâneo, emerge a necessidade de redirecionamento das práticas formativas docentes, em virtude do preparo para o exercício profissional cotidiano, marcado por inconstâncias no contexto escolar, denotado por transformações oriundas dos meios científicos, tecnológicos e informacionais, possibilitando o delineamento de ações que incentivem e contribuam no processo de desenvolvimento dos gestores escolares e professores.

Nesses termos, a formação continuada ganha enfoque, evidenciada pela busca constante por melhorias concernentes ao trabalho docente. Nesse cenário complexo e diversificado, é importante que o princípio formativo continuado atenda às necessidades individuais e/ou coletivas dos gestores e professores, mediante especificidades inerentes ao contexto em que atuam, sob o risco de serem concebidas como ação vazia de significados.

A atuação como profissional da educação denota o viés compreensivo acerca das condições em que se delineia a atividade docente cotidiana, as relações múltiplas estabelecidas no contexto escolar (envolvendo gestão, alunos, professores e comunidade em geral), os conteúdos programáticos presentes na matriz curricular, as estratégias didático/pedagógicas desenvolvidas pelos educadores, as questões legislatórias educacionais, os mecanismos de gestão docente, dentre outros. Nesse aspecto, infere-se que os conteúdos e 
ações abordados pelo curso de atualização em gestão escolar propiciaram estudos e reflexões pertinentes sobre o trabalho dos gestores escolares, em uma perspectiva contributiva no processo de desenvolvimento da profissionalidade dos indivíduos que participaram da ação formativa continuada.

A formação continuada pautada nas necessidades dos gestores e professores potencializou e oportunizou a instauração de espaços colaborativos de compartilhamento de conhecimentos, experiências, angústias e dificuldades, dentre outros, propiciando reflexões críticas individuais e coletivas em meio as incertezas e contradições que perpassam a educação, estimulando a autonomia docente e a mobilização coletiva de luta por melhorias nas condições de trabalho, objetivando valorização social e política dos professores.

Os conhecimentos advindos da trajetória formativa impactam na vida pessoal e profissional dos gestores escolares, podendo contribuir em fatores que perpassam a ação educativa ou constituir-se em uma etapa vazia de significados, no qual tais premissas são determinadas pela forma de desenvolvimento do percurso formativo, se este proporciona a reflexão e ressignificação do trabalho cotidiano ou apenas delineia conteúdos distanciados de sua cultura e contexto de atuação.

Destaca-se a importância da disponibilidade de tempo e espaço para reflexões mais aprofundadas, de forma que possam ser vislumbradas como aportes contributivos no trabalho dos gestores e em seu processo de desenvolvimento profissional, analisando possibilidades de incremento do seu repertório de conhecimentos e práticas, permeando aspectos pessoais, bem como valores e crenças. Nesse sentido, o processo formativo continuado que os sujeitos vivenciaram não disponibilizou tempo viável para reflexões mais aprofundadas, se constituindo como um entrave ao desenvolvimento profissional dos gestores que vivenciaram a experiência formativa.

Os gestores devem apoiar e auxiliar o trabalho docente, instaurando ambientes colaborativos de diálogo, bem como de troca de conhecimentos e experiências, fomentando a aprendizagem compartilhada e objetivando pontos comuns que possam convergir na melhoria da escola e de todos os profissionais que a compõem, em que a formação continuada seja vislumbrada como elemento profícuo e conducente ao desenvolvimento profissional coletivo. 


\section{REFERENCIAS}

BRASIL. Lei 8.069, Dispõe sobre o Estatuto da Criança e do Adolescente (ECA) e dá outras providências. Brasília, 1990. Diário Oficial da União, Brasília, 13 de julho de 1990.

BRASIL. Lei 9.394/96, Diretrizes e Bases da Educação Nacional. Brasília, 1996. Diário Oficial da União, Brasília, 26 de dezembro de 1996.

BRASIL. Conselho Nacional de Educação. Conselho Pleno. Resolução ${ }^{\circ}$ 2, de $1^{\circ}$ de julho de 2015. Define as Diretrizes Curriculares Nacionais para a formação inicial em nível superior (cursos de licenciatura, cursos de formação pedagógica para graduados e cursos de segunda licenciatura) e para a formação continuada. Diário Oficial da União, Brasília, 2 de julho de 2015, seção 1, p. 8-12.

CEARÁ. Lei 13.513. Dispõe sobre o processo de escolha e indicação para o cargo de provimento em comissão, de Diretor junto às Escolas da Rede Pública Estadual de Ensino, e dá outras providências. Fortaleza, 2004. Diário Oficial do Ceará, Fortaleza, 19 de julho de 2004.

CEARÁ. Lei 16.287. Institui a política de ensino médio em tempo integral no âmbito da rede estadual de ensino do Ceará. Fortaleza, 2017. Diário Oficial do Ceará, Fortaleza, 20 de julho de 2017.

CEARÁ. Lei 16.379. Altera a lei no 13.513 , de 19 de julho de 2004. Fortaleza, 2017. Diário Oficial do Ceará, Fortaleza, 16 de outubro de 2017.

DAY, Cristopher. Desenvolvimento profissional de professores - Os desafios da aprendizagem permanente. Trad.: Maria Assunção Flores. Porto: Porto Editora, 2001.

IMBERNÓN, Francisco. Formação continuada de professores. Trad.: Juliana do Santos Padilha. Porto Alegre: Artmed, 2010.

LIBÂNEO, José Carlos; OLIVEIRA, João Ferreira de; TOSCHI, Mirza Seabra. Educação escolar: políticas, estrutura e organização. 7. ed. São Paulo: Cortez, 2009.

LIMA, Maria Socorro Lucena. Estágio e aprendizagem da profissão docente. Brasília: Liber Livro, 2012.

MARCELO, Carlos. Desenvolvimento Profissional Docente: passado e futuro. Revista de ciências da educação, Lisboa, Portugal, n. 8. p. 7-22, jan./abr. 2009. Disponível em: http://dialnet.unirioja.es/ejemplar/220830. Acesso em: 21 jan. 2019.

MATTOS, Sandra Maria Nascimento de; MATTOS, José Roberto Linhares de. Formação continuada de professores de Matemática. Curitiba: Appris Editora, 2019. 
MIZUKAMI, Maria da Graça Nicoletti. Escola e desenvolvimento profissional da docência. In: GATTI, Bernadete Angelina et al. (Org.). Por uma política nacional de formação de professores. São Paulo: Editora Unesp, 2013. p. 23-54.

NASCIMENTO, Francisco Jeovane do. Professores de Matemática iniciantes: um estudo sobre seu desenvolvimento profissional. 2016. Orientadora: Ivoneide Pinheiro de Lima. Dissertação (Mestrado) - Programa de Pós-Graduação em Educação. Universidade Estadual do Ceará, Fortaleza, 2016.

NÓVOA, Antônio. Professores: imagens do futuro presente. Lisboa: Educa, 2009.

OLIVEIRA-FORMOSINHO, João. Desenvolvimento profissional dos professores. In: FORMOSINHO, João (Coord.). Formação de professores: aprendizagem profissional e ação docente. Porto: Porto Editora, 2009. p. 221-284.

PIMENTA, Selma Garrido; LIMA, Maria Socorro Lucena. Estágio e docência. 7. ed. São Paulo: Cortez, 2012.

PONTE, João Pedro da. Estudos de Caso em Educação Matemática. Revista Bolema, Rio Claro, SP, v. 19, n. 25, p. 62-69, ago./dez. 2006.

SILVA, Aida Maria Monteiro. A formação centrada na escola como estratégia institucional. In: GATTI, Bernadete Angelina et al. (Org.). Por uma política nacional de formação de professores. 1. ed. São Paulo: Editora Unesp, 2013. p. 55-72.

SILVA, Maria Oneide Lino da; CABRAL, Carmen Lúcia de Oliveira. Formação continuada - desenvolvimento profissional de professores na escola. Curitiba: Appris editora, 2016.

Enviado em: 23/03/2019

Aprovado em: 14/02/2020 